\title{
Surgical and clinical aspects of colorectal carcinoma and their correlation with BRAFV600E expression in Iraqi patients
}

\author{
By \\ Dr.Suroor Abdulkareem Tarkan ${ }^{*}{ }^{1}$;Specialist surgeon Dr. Ihsan Ali \\ Mohammed $^{* 2}$; Consultant Histopatholgist Dr.Thaeer Jawad \\ Kadhim *3 \\ ${ }^{* 1}$ M.B.Ch.BMinstry of health and enviroment /Iraq; ${ }^{* 2 * 1}$ M.B.CH.B , M.R.C.S Ireland* \\ AL-Yarmook Teaching hospital , Minstry of health and enviroment $/ ;{ }^{* 3}$ M.B.Ch.B \\ FIBMS Path., AL-Yarmook Teaching hospital , Minstry of health and enviroment - \\ Baghdad ,Iraq \\ *Correspondent authur : Dr. Ihsan Ali Mohammed
}

\section{Abstract:}

background:Colorectal cancer (CRC) the most common gastrointestinal cancer in the world. In Iraq it's fifth of the 5 commonest cancer between male $6.33 \%$ and fourth of commonest cancer in between female $4.35 \%$ .Co-morbidity ,mortality and the prognosis depended on several factors like age, gender ,stage , grade ,general health of patient, although the stage and grade are the most important factors . That is why different types and modality of diagnostic tools and methods had been liberated to the field of such a serious disease to altering it's progression. The oncogenic mutation in the kinase region of BRAF gene result in abnormal cellular growth, apoptosis ,resistance, tumor progression and metastasis.Objects /To high light on surgical and clinical criteria of colonic tumorsand specially focus on CRC in Iraqi patients .Alsoto analyses the efficacy of use immunohistochemical expression of BRAFV600E biomarker in colorectal tissues of Iraqi patients.Material and Methods/ In this study, a total of 90patients of colonic tumor referring to Al-Yarmouk Teaching Hospital ,all investigations done for them clinical ,laboratory, radiology and endoscopic with biopsy were done to them. Then after all cases with CRC (60 patients) under gone surgery each case according to standard surgical technique he needed and specimen send to histopathological examination , form each case 2 slides was done at a private lab. One For H\&E stain and, second one for IHC.Results/In our study the CRC is more common in old age, males , left colon and most cases of high grade (III) and high stage (III and IV) and more than $5 \mathrm{~cm}$. The current study shown a correlation of BRAF 
expression with age, tumor size, tumor grade and stage of CRC patients is significant value, but with other variables are not significant correlation in CRC pateints.conclucion /According to our result most of the CRC cases occurs in the 7th decade of life and most of the cases were stage 3 tumor . We found significant correlation between BRAF expression and patient's age, tumor site, tumor size, pathological stage and histological grade.

Key words/Colorectal cancer (CRC), BRAF and immunohistochemistry ( IHC)

\section{$\underline{\text { Introduction }}$}

Colorectal cancer (CRC ) is a serious and common health problem worldwide . It's $3^{\text {rd }}$ most common visceral malignancy with 1.2 million new cases diagnosed in 2012 (1). It's remain major health problems due to limitation of early diagnosis and treatment of advanced cases (2) .Over $50 \%$ of CRC develop metastasis that is why mortality and morbidity are still high(3,4). more studies had been published to describe all aspects of CRC specially in tumor genesis and more attention on early detection , treatment modalities $(4,5)$. The discovery of additional prognostic markers might resume the emergence of new guidelines for better management of $\mathrm{CRC}(6)$.

dissemination ,recurrence, response to treatment , or detection of risk factors in healthy peoples (7) .

BRAF is a member of the RAS/RAF/MEK/ERK pathway .Activation of this pathway might signal to tumor-genesis process (7) .Different aberrations of BRAF have been reported in various malignancies (8).

In BRAF gene mutation testing has emerged as an important tool for diagnosis , prognosis , treatment of multiple cancer types like metastatic myeloma ,papillary thyroid carcinoma and CRC(8).

V600E is the most common mutation for the BRAF (9) .The advantage of Immunohistochemistry (IHC) lies in it's availability and minimal amount of tissue needed . This study aimed to :

1-High light on surgical and clinical criteria of the CRC in Iraqi patients. 
2-Analyses the efficacy of use immunohistochemical expression of BRAFV600E biomarker in colorectal tissues of Iraqi patients in differentiation of benign and malignant cases and to correlate the expression of BRAFV600E biomarker with other variable patients age ,Gender ,tumor size , site ,histological type , grade and stage.

\section{Material and Method}

In this pre-prospective study, a total of 90 patients of colonic tumor referring to Al-Yarmouk Teaching Hospital during period of January 2019 to May 2020, all investigations done for them clinical, laboratory, radiology and endoscopic (proctoscopy, sigmoidoscopy and colonoscopy) with biopsy were done to them. The results were conclusive in 60 patents and the diagnosis established as cases of CRC.

In 30 cases the diagnosis was not conclusive (with adenomaplus lowgrade of dysplasia), Then after all cases with CRC (60 patients) undergone surgery each case according to standard surgical technique he needed andspecimen send to histopathological examination, form each case 2 slides was done at a private lab. One for H\&E stain and, second one forIHC.

The 4 types of surgical resection has done to patients with established diagnosis CRC (17):

1-Right hemicolectomy (limited or extended)

2-Left hemicoloctomy (limited or extended )

3-Anterior rectosigmoidactomy

4-Abdominioperineal resection of (sigmoid, rectum and anus)

Details information and description of tumors macroscopic and microscopic were recorded like size, shape ,extent and depth ofe233e23322 wall invasion ,local adjacent organ invasion, vascular lympthaticorgan metastasis, clearness of edges of resection .

Also, we did both positive controltissues and negative control tissuesto confirm detection of brown protein (DAB) reaction production at site of target antigen of BRAFV600E gene. 
Lastly the statistical analysis of result were done by using the computerized database structure, statistic package for social sciences (SPSS v .20) computer software was used for this purpose .Frequency distribution was done for the study variable .Data were reported and presented as numbers (n), percentage (\%) results of obtained data were presented in tables and graphs and the correlation toBRAFV600E considered significant when $P$ value lesser than 0.05 .

\section{Results}

Table (1)Clinic-surgical parameters selected for analysis of CRC cases . Regarding tumor site CRC from right colon (ascending colon and transverse colon) comprised 35\% 21cases, while from left colon (descending colon, sigmoid and rectum) encompassed 65\%39 cases .So the highest percentage in left colon and the correlation is significant at 0.01(p-value0.003) .The adenoma cases from right colon (ascending colon and transverse colon) comprised 26.6\% 8cases, while tumors from left colon (descending colon, sigmoid and rectum) encompassed 73.3\% 22cases. Regarding histological type highest percent of CRC cases were adenocarcinoma 50cases $83.3 \%$, while highest percentage of adenoma sample were tubulovillous 12cases $40 \%$, no significant correlation between histological type of CRC and BRAF expression p-value 0.44 .

\begin{tabular}{|c|c|c|c|}
\hline $\begin{array}{c}\text { Pathological } \\
\text { parameters }\end{array}$ & NO & $\%$ & Total \\
\hline Age & 6 & 10 & $100 \%$ \\
$40-49$ & 9 & 15 & \\
$50-59$ & 15 & 25 & \\
$60-69$ & 18 & 30 & \\
$70-79$ & 12 & 20 & \\
$80-90$ & 40 & 66.7 & $100 \%$ \\
& 20 & 33.3 & \\
\hline Gender & 39 & 65 & $100 \%$ \\
Male & 21 & 35 & $100 \%$ \\
Female & 24 & 40 & \\
\hline Site of carcinoma & 36 & 60 & $100 \%$ \\
Lt & 12 & 20 & \\
\hline Rt & & & \\
\hline Size of carcinoma & & & \\
\hline 5 & & & \\
\hline Stage & & & \\
I & & & \\
\hline
\end{tabular}




\begin{tabular}{|c|c|c|c|}
\hline II & 15 & 25 & \\
III & 18 & 30 & \\
IV & 15 & 25 & $100 \%$ \\
Grade & 15 & 25 & \\
Well differentiation & & 18.3 & \\
(grade I) & 11 & 56.7 & \\
Moderate & 34 & & \\
differentiation(grade & & & \\
II) & & & \\
Poor & & 83.3 & \\
differentiation(grade & 10 & 16.6 & \\
III) & & & \\
\hline Histological type & & $100 \%$ \\
Adenocarcinoma & & 20 & \\
Mucinous carcinoma & 1 & 20 & \\
\hline BRAF expression & 2 & 30 & \\
Age & 2 & 20 & \\
$40-49$ & 2 & & \\
$50-59$ & & & \\
$60-69$ & & & \\
$70-79$ & & & \\
$80-90$ & & & \\
\hline
\end{tabular}

Table (2) The correlation between the age , Gender and BRAF expression in 60 studied CRC cases with highest age rangebetween 70-79 years and highest incidence in males . The correlation of BRAF with age is significantat 0.01 level (p-value 0). But with Gender is not significant at p-value 0.26 .

\begin{tabular}{|c|c|c|c|c|}
\hline Pathological parameters & NO & $\%$ & $\begin{array}{c}\text { Positive } \\
\text { BRAF }\end{array}$ & $\%$ \\
\hline Age 40-49 & 6 & 10 & 1 & 10 \\
$50-59$ & 9 & 15 & 2 & 20 \\
$60-69$ & 15 & 25 & 2 & 20 \\
$70-79$ & 18 & 30 & 3 & 30 \\
$80-90$ & 12 & 20 & 2 & 20 \\
& & & & \\
\hline Gender & & & & \\
Male & 40 & 66.7 & 5 & 8.3 \\
\hline
\end{tabular}

Table (3)The correlation between the tumor size ,stage, grade and BRAF expression in 60 studied CRC cases .Regarding tumor size correlation is significant at 0.01 (p-value 0.003 ) with highest percentage $>5 \mathrm{~cm}$. Regarding stage distribution for the cases are stage III the percent and positive BRAF cases shown correlation is significant at 0.01(p- 
value0). Regarding tumor grade the highest percrntage are poorly differentiated tumors and correlation is significant at 0.01 (p-value $0.003)$.

\begin{tabular}{|c|c|c|c|c|}
\hline Pathological parameters & NO & $\%$ & $\begin{array}{c}\text { BRAF } \\
\text { positive }\end{array}$ & $\%$ \\
\hline Size of carcinoma & & & & \\
$<5$ & 24 & 40 & 4 & 6.6 \\
$>5$ & 36 & 60 & 6 & 10 \\
\hline Stage & 12 & 20 & 3 & 30 \\
I & 15 & 25 & 1 & 10 \\
II & 18 & 30 & 2 & 20 \\
II & 15 & 25 & 4 & 40 \\
\hline Grade & 15 & 25 & 4 & 6.6 \\
Well differentiation (I) & 11 & 18.3 & 0 & 0 \\
Poderate differentiation(II) & & & & \\
\hline & 34 & 56.7 & 6 & 10 \\
\hline
\end{tabular}

Table (4)Clinico-surgical parameters selected for analysis of 30 adenoma cases , all cases shows low grade dysplasia and non of them showed reactivity for BRAFV600E biomarker . The table shows that incidence of adenoma in our study the commonest age was between 30-49 years and it's more common between males and on left colon . The common adenoma type is tubulovillous and commonest size is between $1-3 \mathrm{~cm}$.

\begin{tabular}{|c|c|c|c|}
\hline Parameter & $\begin{array}{c}\text { No. of adenoma } \\
\text { cases }\end{array}$ & Percentage & Total \\
\hline Adenoma age & 10 & 33.3 & $100 \%$ \\
$30-49$ & 7 & 23.3 & \\
$50-59$ & 6 & 20 & \\
$60-69$ & 4 & 13.3 & \\
$70-79$ & 3 & 10 & $100 \%$ \\
$80-90$ & 18 & 60 & \\
\hline Gender & 12 & 40 & $100 \%$ \\
Male & 22 & 73.3 & \\
Female & 8 & 26.6 & \\
\hline Adenoma site & & 30 & \\
Lt & 9 & 50 & $100 \%$ \\
Rt & 15 & 20 & \\
\hline Adenoma size & 6 & 26.6 & \\
$<1$ & 8 & & \\
$1-3$ & & & \\
\hline 3 & & & \\
\hline Adenoma type & & & \\
Tubular & & & \\
\hline
\end{tabular}




\begin{tabular}{|c|c|c|c|}
\hline Villous & 10 & 33.3 & \\
Tubulovillous & 12 & 40 & \\
\hline
\end{tabular}

Table (5) show distribution od cases according to type of surgical operation down for them, show the highest percentage of cases subjected to left colon surgery with or without permanent colostomy .

\begin{tabular}{|c|c|c|c|}
\hline Type of operation & total & $\begin{array}{c}\text { No. of } \\
\text { cases }\end{array}$ & $\%$ \\
\hline Rt. Hemicoloctomy & 21 & 21 & $35 \%$ \\
\hline Lt. Hemicoloctomy & 39 & 10 & $16.6 \%$ \\
\hline Anterior Rectosigmoidoctomy & & 9 & $15 \%$ \\
\cline { 4 - 4 } $\begin{array}{c}\text { Abdominopreneal resection of Lt. colon , rectum and anal } \\
\text { channel plus permanent colostomy }\end{array}$ & 20 & $33.3 \%$ \\
\hline
\end{tabular}

\section{$\underline{\text { Discussion }}$}

In this study we high -light on the clinic-surgical criteria of CRC in Iraqi patients and correlate it with tissues, immunohistocompatibility to anti BRAF V600E .

In our study patients age range from 40-90, but the highest percentage of them in age range 70-90 (18cases 30\%) .This result agree with WolFgan et al 2009 study who showed that 69\% of CRC cases among older ages above 60 (10) , also with reports from American cancer society statistics 2014 , which cleared that incidence of CRC is more than 15 time higher in adults of 50 years and older (11). Which may be related to change in type of food, reduced physical activity, metabolic syndrome (12) .

In our study there is significant correlation between age and BRAF expression with p-value 0 at 0.01 level.

CRC cases more common in male (40 cases 66.7\%) in compare to female (20cases 33.3\%) . but no significant correlation between BRAF and Gender distribution p-value 0.26 at 0.01level.

Several study find sameGender distributionRim et al 2009 , Rozen et al $2012(13,14)$ these study reveal high incidence of CRC male $66.7 \%$ than female $33.3 \%$. The cause of third difference is not clear may be hormonal (15) . 
Regarding: - Tumor size and site highest percentage of CRC were more than $5 \mathrm{~cm}$ (36cases 60\%). And effecting Lt colon (descendingcolon, sigmoid and rectum) (65\% 39cases) with significant correlation betweentumor site, size and BRAF expression p-value 0.003at 0.01 level.

Other studies done in Iraqreached thensame result Left colon 65\%, Right colon 35\% (16,17).

Gado et al., 2014 describe incidence of (68\% of CRC) in Left colon in Egypt (18). So as Shin et al 2014 incidence of 69.5\% in Left colon (19).

Regarding histologicaltype, grade, stage: -most case in our study were adenocarcinoma (83.3\% 50cases ) and poorly differentiated grade III (56.7\% 34cases) and 55\% were stage III and IV (55\% 33 cases) .histological typeof tumor no significant correlation with BRAF expression of p-value 0.44 while our study reveal significant correlation between higher stage and grade of CRC with BRAF expression of pvalue 0 , and p-value 0.003 respectively .

Adenocarcinoma incidence in Godaet al., andAzadehet al., studies agree with ourstudy, they found (91\%,83.2\% )respectively of cases of CRC wereadenocarcinoma (20) .

Also Dolatkhah et al.,2015 said that most frequent type of CRC isadenocarcinoma (21) .

Our study unlike previous studies regarding stage and grade of CRC. Harmooshy who reported that $51.2 \%$ of cases in their work were grade I

While Othman stated the most of caseswere of gradeII (moderate differential about $68.6 \%$ (23).

Increase age associated with increase stage and poor prognosis (55\% 33cases) were in high stage and carry significant correlation between high stage 3 \&4) and BRAF expression with p-value 0. And this agrees with Fiona Day et al which founded that $60 \%$ of CRC in high stage and strongly correlation with BRAF expression (24).

Also, Sara Sajantet al., study agree with our study result (25). 
Regarded BRAFexpression: the BRAF biomarker was positive in 10 cases (16.6\%) and it agree with other studies .A study whopublished at 2017 show that BRAF mutation of any codon in was detection 137 of 1014 (13.5\%) with mutation CRC. Another study published in 2014showBRAF mutation in 63 out of 477 (13.2\%) by IHC (24).

Regarding adenoma group: adenoma patients age range from 30-90years highest percentageof them rang 30-49 10cases 33.3\% more commonest in male 18 cases $60 \%$.

Common site of predilection is Left colon $73.3 \%$ 22cases .50\% of cases 15cases their size between $1-3 \mathrm{~cm}$ and $40 \%$ were tubulovillous adenoma and none of them showed reactivity for BRAF biomarkers .

Our study disagreewith Beach et al 2005 who detect BRAF mutation in $30 \%$ of tubular adenoma (26), while Lee et al 2005 mentioned that mutant BRAF expression was found if it's serrated adenomas or hyperplastic type (27) .

Chan et al.,concluded that acquisition of BRAF mutation will progresshyperplastic polyp to serrated adenoma carcinoma pathway (28). Recent published data demonstrate a high concordance $98 \%$ of BRAF mutation between primary Ab and metastatic tumors (Italiano et al 2010)

\section{Conclusion}

1-According to our result most of the CRC cases occurs in the $7^{\text {th }}$ decade of life and most of the cases were stage 3 tumor .

2-While all cases of suspected colonic polype show low grade dysplasia and none of them showed reactivity for BRAFV600E biomarker and incidence of adenoma in our study the commonest age was between 3049 years and it's more common between males and on left colon alsoIt's mainly of tubulovillous type and commonest size is between $1-3 \mathrm{~cm}$. .

2-We found significant correlation between BRAF expression and patient's age, tumor site, tumor size, pathological stage, histological grade 
while there is no correlation between BRAF expression and patient's Gender, histological type.

3-BRAFV600E mutation was positive only in $16.6 \%$ of carcinoma group and associated significant with different clinical and pathological factors. Therefore, we infer that BRAF V600E mutation may be a promising tool for early detection of micro metastatic circulation tumor cells in CRC patients.

\section{References}

1-Ferlay J, Soerjomataram I, Dikshit R, Eser S, Mathers C, Rebelo M, Parkin DM, Forman D, Bray F. Cancer incidence and mortality worldwide: sources, methods and major patterns in GLOBOCAN 2012. International journal of cancer. 2015 Mar 1;136(5):E359-86.

2-Akhter M, Inoue M, Kurahashi N, Iwasaki M, Sasazuki S, Tsugane S. Dietary soy and isoflavone intake and risk of colorectal cancer in the Japan Public Health Center-Based Prospective Study. Cancer .Epidemiology and Prevention Biomarkers. 2008 Aug 1;17(8):2128-35

3-Bilchik AJ, DiNome M, Saha S, Turner RR, Wiese D, McCarter M, Hoon DS, Morton DL. Prospective multicenter trial of staging adequacy in colon cancer: preliminary results. Archives of Surgery. 2006 Jun 1;141(6):527-34.

4-Manfredi S, Bouvier AM, Lepage C, Hatem C, Dancourt V, Faivre J. Incidence and patterns of recurrence after resection for cure of colonic cancer in a well defined population. British Journal of Surgery. 2006 Sep 1;93(9):1115-22.

5-Galizia G, Gemei M, Del Vecchio L, Zamboli A, Di Noto R, Mirabelli P, Salvatore F, Castellano P, Orditura M, De Vita F, Pinto M. Combined CD133/CD44 expression as a prognostic indicator of disease-free survival in patients with colorectal cancer. Archives of surgery. 2012 Jan 16;147(1):18-24.

6-Tejpar S, Bertagnolli M, Bosman F, Lenz HJ, Garraway L, Waldman F, Warren R, Bild A, Collins-Brennan D, Hahn H, Harkin DP. Prognostic 
and predictive biomarkers in resected colon cancer: current status and future perspectives for integrating genomics into biomarker discovery. The oncologist. 2010 Apr;15(4):390.

7-Langan RC, Mullinax JE, Raiji MT, Upham T, Summers T, Stojadinovic A, Avital I. Colorectal cancer biomarkers and the potential role of cancer stem cells. Journal of Cancer. 2013;4(3):241.

8-Ogino S, Shima K, Meyerhardt JA, McCleary NJ, Ng K, Hollis D, Saltz LB, Mayer RJ, Schaefer P, Whittom R, Hantel A. Predictive and prognostic roles of BRAF mutation in stage III colon cancer: results from intergroup trial CALGB 89803. Clinical Cancer Research. 2012 Feb 1;18(3):890-900.

9-Asl JM, Almasi S, Tabatabaiefar MA. High frequency of BRAF protooncogene hot spot mutation V600E in cohort of colorectal cancer patients from Ahvaz City, southwest Iran. Pakistan journal of biological sciences:

PJBS. 2014 Apr 1;17(4):565-9.

10-Brozek W, Kriwanek S, Bonner E, Peterlik M, Cross HS. Mutual associations between malignancy, age, gender, and subsite incidence of colorectal cancer. Anticancer research. 2009 Sep 1;29(9):3721-6 .

11-American cancer society (2014) colorectal cancer.

12-Hong SN, Kim JH, Choe WH, Han HS, Sung IK, Park HS, Shim CS. Prevalence and risk of colorectal neoplasms in asymptomatic, averagerisk screenees 40 to 49 years of age. Gastrointestinal endoscopy. 2010 Sep 1;72(3):480-9.

13-Rim SH, Seeff L, Ahmed F, King JB, Coughlin SS. Colorectal cancer incidence in the United States, 1999-2004: an updated analysis of data from the National Program of Cancer Registries and the Surveillance, Epidemiology, and End Results Program. Cancer. 2009 May 1;115(9):1967-76.

14-Rozen P, Liphshitz I, Barchana M. Changing epidemiology of colorectal cancer makes screening sigmoidoscopy less useful for identifying carriers of colorectal neoplasms. Digestive diseases and sciences. 2012 Aug;57(8):2203-12. 
15-Murphy G, Devesa SS, Cross AJ, Inskip PD, McGlynn KA, Cook MB. Gender disparities in colorectal cancer incidence by anatomic subsite, race and age. International journal of cancer. 2011 Apr 1;128(7):1668-75.

16-Rahman, M.and Al-Janabi, K. (2000) .Pattern of colorectal and anal tumor and its surgical treatment .J.Fac. Med, (1):38-44

17- Hassan, H. and Sameen ,A. 2002 colorectal carcinoma , presentation and pattern of surgical management at the university hospital . A thesis submitted ti Iraqi commission for medical specializations :209

18-Gado A, Ebeid B, Abdelmohsen A, Axon A. Colorectal cancer in Egypt is commoner in young people: is this cause for alarm?. Alexandria Journal of Medicine. 2014;50(3):197-201

19-Shin IY, Sung NY, Lee YS, Kwon TS, Si Y, Lee YS, Oh ST, Lee IK. The expression of multiple proteins as prognostic factors in colorectal cancer: cathepsin D, p53, COX-2, epidermal growth factor receptor, CerbB-2, and Ki-67. Gut and liver. 2014 Jan;8(1):13.

20-Azadeh S, Reza FS, Sara A, Mohsen V, Bijan MD, Zali ZR. Four years incidence rate of colorectal cancer in Iran: a survey of national cancer registry data-implications for screening. Asian Pacific Journal of Cancer Prevention. 2012;13(6):2695-8.

21-Dolatkhah R, Somi MH, Bonyadi MJ, AsvadiKermani I, Farassati F, Dastgiri S. Colorectal cancer in Iran: molecular epidemiology and screening strategies. Journal of cancer epidemiology. 2015 Jan 15;2015

22-Al-Harmooshy MB. Immunohistochemical study of CEA and BCL2 Expression in Colorectal Adenocarcinoma and its Correlation with Some Pathological Parameters. Medical journal of Babylon. 2011;8(2).

23-Abdulhussain, S. and Othman ,O (2012).Epidemiological study of colorectal and anal cancer inKirkukcity . Iraqi j of Gastro center 6 (1):33-

24-Day F, Muranyi A, Singh S, Shanmugam K, Williams D, Byrne D, Pham K, Palmieri M, Tie J, Grogan T, Gibbs P. A mutant BRAF V600Especific immunohistochemical assay: correlation with molecular mutation 
status and clinical outcome in colorectal cancer. Targeted oncology. 2015 .Mar 1;10(1):99-109

25-Sajanti S, Sirniö P, Väyrynen JP, Tuomisto A, Klintrup K, Mäkelä J, Ristimäki A, Mäkinen MJ. VE1 immunohistochemistry accurately detects BRAF V600E mutations in colorectal carcinoma and can be utilized in the detection of poorly differentiated colorectal serrated adenocarcinoma. .VirchowsArchiv. 2014 Jun;464(6):637-43

26-Beach R, Chan AO, Wu TT, White JA, Morris JS, Lunagomez S, Broaddus RR, Issa JP, Hamilton SR, Rashid A. BRAF mutations in aberrant crypt foci and hyperplastic polyposis. The American journal of .pathology. 2005 Apr 1;166(4):1069-75

27-Lee EJ, Choi C, Park CK, Maeng L, Lee J, Lee A, Kim KM. Tracing origin of serrated adenomas with BRAF and KRAS mutations. .VirchowsArchiv. 2005 Sep;447(3):597-602

28-Chan TL, Zhao W, Leung SY, Yuen ST. BRAF and KRAS mutations in colorectal hyperplastic polyps and serrated adenomas. Cancer research. .2003 Aug 15;63(16):4878-81

29-Italiano A, Hostein I, Soubeyran I, Fabas T, Benchimol D, Evrard S, Gugenheim J, Becouarn Y, Brunet R, Fonck M, François E. KRAS and BRAF mutational status in primary colorectal tumors and related metastatic sites: biological and clinical implications. Annals of surgical .oncology. 2010 May;17(5):1429-34 